\title{
Long-term structural and durability performances of reinforced concrete elements strengthened in flexure with CFRP laminates: a research project
}

\author{
José Sena-Cruz, J. Ricardo Cruz, Luís Correia \\ ISISE, University of Minho, Guimarães, Portugal
}

Susana Cabral-Fonseca

Laboratório Nacional de Engenharia Civil, Lisbon, Portugal

Julien Michels, Christoph Czaderski

Empa Materials Science and Technology, Dübendorf, Switzerland

Contacting author: jsena@civil.uminho.com

\begin{abstract}
Over the last two decades, the use of fibre reinforced polymer (FRP) materials for strengthening existing reinforced concrete (RC) structures has been constantly increasing, and nowadays it is considered state-of-the-art and is frequently used by the construction industry. Typically, these composite materials are externally bonded (EBR technique) or near-surface-mounted (NSM technique) on the elements to be retrofitted. Although substantial research has been performed and design rules have been established, most studies focused on the short-term structural performance of the strengthened elements without considering their long-term behaviour. The FRPLongDur R\&D project aims at studying the long-term structural behaviour and durability performance of RC elements strengthened in flexure with Carbon FRP (CFRP) laminates according to the EBR and NSM techniques, under various real environmental exposure and loading conditions (carbonation, moisture, chlorides, thermal and freeze-thaw cycles, initial FRP pre-strain level and sustained loading). For this purpose, several prototypes have been installed in different sites of Portugal, each one being representative of the above listed environments under investigation, currently considered as the most critical exposure conditions. Additionally, test specimens of the materials involved - CFRP laminate, epoxy adhesive and concrete - and bond specimens have been prepared and installed near the other prototypes in order to evaluate their own durability. The present paper presents the initial insights on the ongoing FRPLongDur project.
\end{abstract}

Keywords: Strengthening; CFRP laminates; durability; long-term behaviour; accelerated ageing; outdoor ageing. 


\section{Introduction}

Nowadays, carbon fibre reinforced polymer (CFRP) materials for strengthening existing reinforced concrete $(\mathrm{RC})$ structures are considered state-ofthe-art. Durability of structures strengthened with CFRP has been intensively studied under laboratorial conditions using accelerated ageing protocols. However, very few studies of durability have been performed in real outdoor conditions. Moreover, the relationship between accelerated ageing tests under laboratorial conditions and real outdoor ageing conditions for assessing the durability of these systems is not fully understood [1].

Few publications on this topic can be found in literature. Some of them include both types of exposure conditions, i.e. accelerated ageing and outdoor conditions and they do an attempt to establish relationships between both [1-5]. Other publications only focused on the durability under outdoor conditions [6-9]. In general, the level of damage observed in structures exposed to accelerated ageing in laboratorial conditions is much greater than the one of outdoor conditions.

This paper presents an overview of the ongoing FRPLongDur research project, namely, a brief description of the project, preparation and installation of the specimens and some preliminary results.

\section{FRPLongDur description}

Figure 1 presents the flowchart of the research project. The main objective of this project is to contribute for the knowledge on long-term structural behaviour and durability performance of $\mathrm{RC}$ elements strengthened in flexure with CFRP laminates according to the EBR and NSM techniques under various real environments. The project involves three main components: (i) an experimental program, (ii) numerical simulations, and (iii) design recommendations. Two distinct scales are used: (i) specimens for material and bond characterization, and (ii) full scale slabs. Finally, this project involves three institutions, namely the University of Minho, the Portuguese National Laboratory of Civil Engineering (LNEC) and the Swiss Federal Laboratories for Materials Science and Technology (Empa).

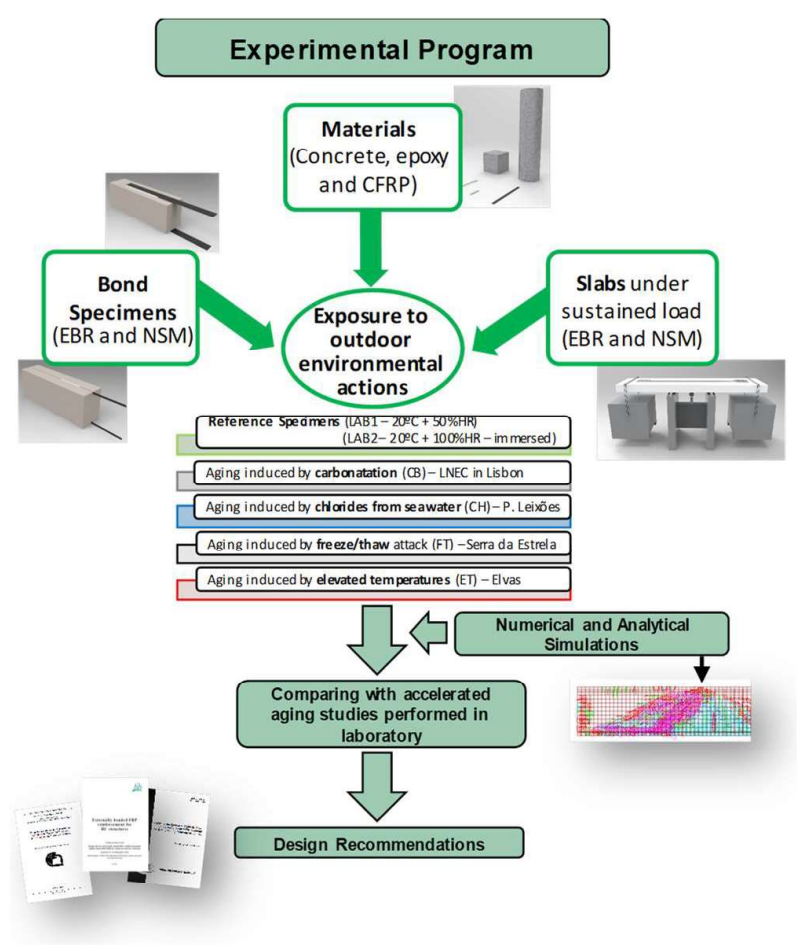

Figure 1. Research project flowchart.

\subsection{Specimens}

In order to evaluate the materials' durability, a set of specimens was defined including samples of (i) concrete (cylinders of $150 \mathrm{~mm}$ diameter and 300 $\mathrm{mm}$ high), (ii) epoxy adhesive (dog-boned shaped specimens according to ISO 527-2) and, (iii) CFRP laminate (specimens with different width and 250 $\mathrm{mm}$ of length, according to ISO 527-5).

For the assessment of the durability of bond CFRP/concrete systems for both EBR and NSM techniques: (i) EBR bond specimens materialized with concrete prisms with $200 \times 200 \times 400[\mathrm{~mm}]$ were adopted. On their lateral surfaces (parallel to the casting direction), a CFRP laminate with a crosssection of $50 \times 1.2[\mathrm{~mm}]$ was applied over a bond length $\left(L_{b}\right)$ of $220 \mathrm{~mm}$ in each side; (ii) NSM bond specimens consisted on a concrete cube $(200 \mathrm{~mm}$ of edge) with a CFRP laminate (cross-section of $10 \times 1.4[\mathrm{~mm}]$ installed on their lateral surfaces, with $L_{\mathrm{b}}=60 \mathrm{~mm}$ were adopted.

The FRPLongDur project also included the execution of full-scale RC slabs. These concrete 
slabs present a rectangular cross-section of $600 \times 120[\mathrm{~mm}]$ with a total length of $2600 \mathrm{~mm}$. The bottom steel reinforcement was composed of 5 steel bars of $8 \mathrm{~mm}$ diameter $(4 \varnothing 8)$ whereas $3 \varnothing 6$ were used as top steel reinforcement. Steel stirrups of $6 \mathrm{~mm}$ diameter spaced at $300 \mathrm{~mm}$ were used. A concrete cover of $20 \mathrm{~mm}$ was set. Four distinct strengthening solutions were adopted including two non-prestressed (EBR and NSM) and two prestressed systems (MA - mechanical anchorage and GA - gradient anchorage). For the case of the EBR slabs, a CFRP with a cross-section of $100 \times 1.2$ [mm] was used. On the NSM slab, four CFRP laminates were used with a cross-section of $10 \times 1.4$ [mm]. On both pre-stressed systems (MA and GA), a CFRP laminate with a cross-section of $50 \times 1.2[\mathrm{~mm}]$ was used, with a pre-strain of $0.4 \%$. To assess to the synergic effects of creep and the environmental action (of each selected environmental exposure condition), the slabs were submitted to a sustained load with a magnitude of about $40 \%$ of the ultimate load carrying capacity of the corresponding slab under a four-point bending test configuration.

\subsection{Environmental exposure conditions}

Six different environmental exposure conditions (EEC) were selected. For each one, different experimental stations (ES) were created and placed in Portugal in different sites, representing each one the EEC (see Figure 2). These EEC include: (i) two environments characterized by constant temperature and humidity and no ultraviolet (UV) radiation, LAB1 $\left(20^{\circ} \mathrm{C}\right.$ and $\left.55 \% \mathrm{RH}\right)$ and $\mathrm{LAB} 2$ (specimens immerse in tap water at $20^{\circ} \mathrm{C}$ ) located at the Structural Laboratory (LEST) of UMinho, Guimarães; (ii) one outdoor environment inducing ageing mainly by carbonation (CB), at the National Laboratory of Civil Engineering (LNEC), Lisbon ($38.77^{\circ} \mathrm{N}, 9.13^{\circ} \mathrm{W}$ ); (iii) one outdoor environment inducing ageing mainly by freeze-thaw cycles (FT), at Lagoa Comprida's Dam (EDP), Serra da Estrela, Seia $\left(40.37^{\circ} \mathrm{N},-7.65^{\circ} \mathrm{W}\right)$; (iv) one outdoor environment inducing ageing mainly by the elevated temperatures (ET), at the factory of S\&P Clever and Reinforcement Company, Elvas $\left(38.89^{\circ} \mathrm{N},-7.15^{\circ} \mathrm{W}\right)$; and $(v)$ one outdoor environment inducing ageing mainly by chlorides from sea water $(\mathrm{CH})$, at Porto de Mar de Viana do
Castelo (APDL), Viana do Castelo $\left(41.68^{\circ} \mathrm{N}\right.$, $8.82^{\circ} \mathrm{W}$ ). The specimens installed in LAB1 and LAB2 are used as control specimens for establishing comparisons with the other EEC's.

\subsection{Monitoring and testing}

The FRPLongDur project includes the collection of the specimens (material samples and bond specimens) after $1,2,3,4,6,8$ and 10 years of exposure to perform destructive tests to assess the level of degradation, from physical, chemical and mechanical points of view. For the full-scale slabs, the plan includes periodic monitoring of the following parameters: (i) mid-span displacement, (ii) crack width and depth, (iii) compressive strain on the concrete at mid-span, and, (iv) strains along the CFRP laminate.

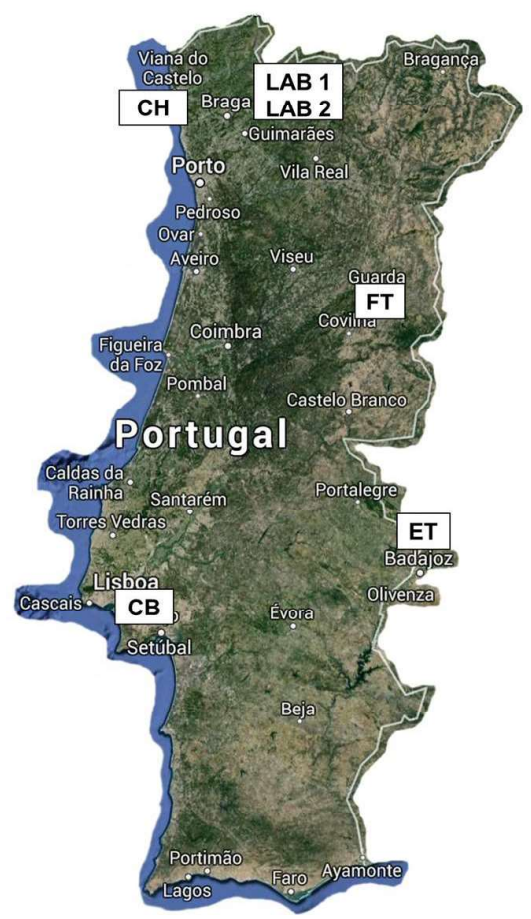

Figure 2. Geographical location of the experimental stations of the FRPLongDur project.

\subsection{Numerical and analytical simulations}

Based on the results obtained from the behaviour observed on the specimens subjected to the EEC, it is planned to establish numerical and analytical simulations for better understanding the phenomena observed and to extend the ageing 
tests in order to predict the working service life of this type of structures.

\subsection{Correlations between artificial and real ageing conditions}

Based on the results obtained from the work described on the previous sections and using also the information on the existing literature, it is planned to establish correlations between the effects caused in the specimens by the artificial at the lab and natural outdoor ageing conditions.

\subsection{Design recommendations}

The ultimate goal of this project is to establish design recommendations for application of these strengthening systems. In this task, it will be focused on the establishment of parameters able to characterize the long-term degradation of these systems in order to include these parameters in the design procedures.

\section{Specimen's preparation and installation of ES}

All the concrete specimens were cast from a unique concrete mixture batch (Figure 3). $12 \mathrm{~m}^{3}$ of fresh concrete were used to cast 140 cylinders, 90 cubes, 90 prims and 30 slabs (see also Section 2.1). In the case of the slabs, prior the concreting, several gauge sensors were installed. A concrete $\mathrm{C} 30 / 37$ XC4(P) CL 0.40 dmax 12.5 S4 was adopted. Steel bars of A400 NR SD were used as reinforcement for the slabs.
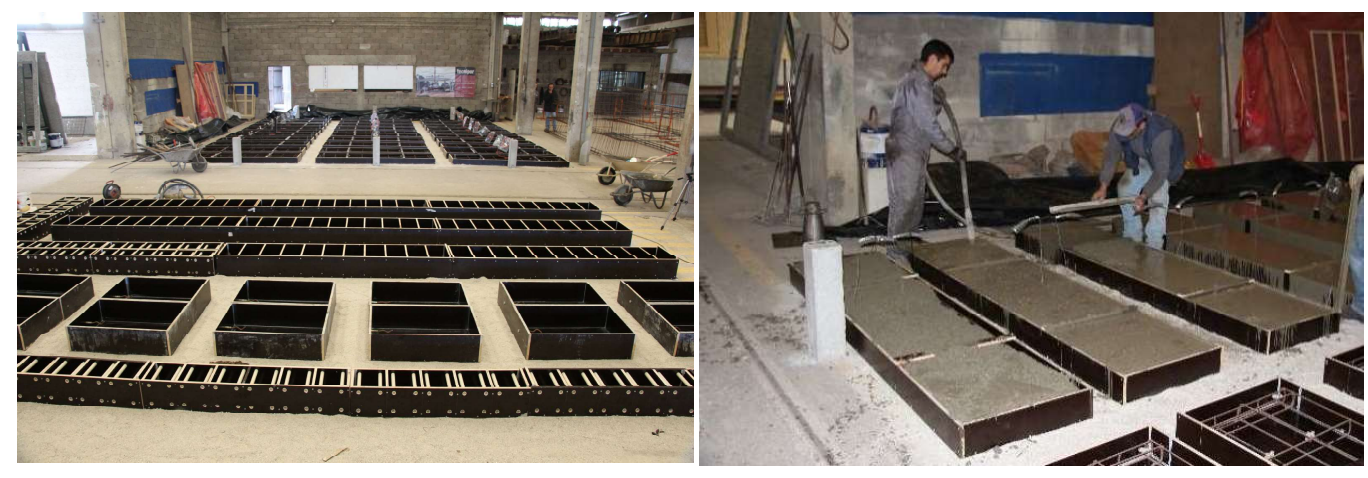

Figure 3. Casting.

The installation of the CFRP laminates in the different specimen types, followed the type protocols used with the EBR, NSM, MA and GA techniques. Further information about these aspects can be found in $[5,10,11]$.

Currently, the installation of the different experimental stations (ES) is already concluded, as depicted in Figure 4. Typically, in situ installation took one day. However, several weeks were necessary for the preparation of all the specimens used in each ES.

\section{Preliminary results}

\subsection{Tests at T0}

At the onset of the installation of the ES (TO), an experimental campaign composed of (i) direct pull- out tests on NSM specimens (DPT-NSM), (ii) singlelap shear tests on EBR specimens (SLT-EBR) and, (iii) flexural tests with RC slabs (EBR, NSM, MA and $G A)$, were performed. In addition, tests on samples of the involved materials were also done. These tests were performed for the sake of comparison between aged and unaged specimens.

\subsubsection{Bond tests}

The T0 experimental campaign includes 8 specimens for assessing the bond performance of EBR and NSM techniques (4 specimens per technique). For EBR specimens, a CFRP laminate with a cross-section of $50 \times 1.2[\mathrm{~mm}]$ with a $L_{b}=$ $220 \mathrm{~mm}$ was applied; and on NSM specimens, it was used a CFRP of $10 \times 1.4[\mathrm{~mm}]$ along a $L_{b}=$ $60 \mathrm{~mm}$. The specimen's geometry and test configuration adopted for the bond NSM and EBR 
tests is shown in Figure $5 a$ and Figure $5 b$, respectively. Additional details about specimen's geometry and test setup can be found in the literature (EBR - [10], NSM - [5]).

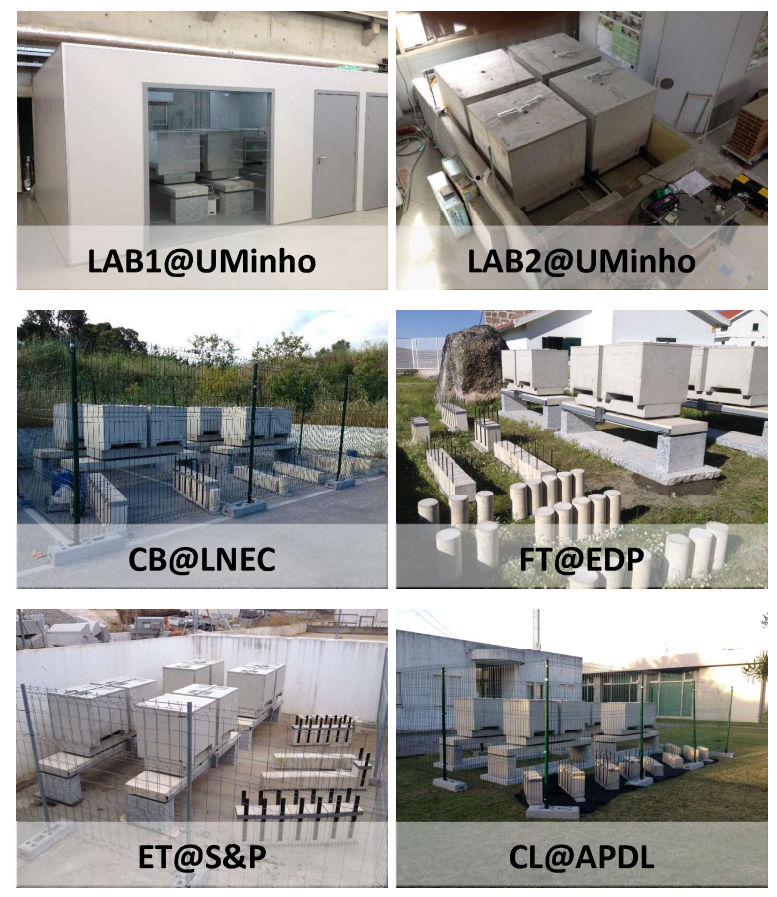

Figure 4. Experimental stations of FRPLongDur.

\subsubsection{Flexural tests with RC slabs}

Details about the experimental campaign with the $\mathrm{RC}$ slabs are presented in Table 1 . One slab was used as reference slab (SL_REF_TO). The slab SL_NSM_TO was strengthened with four laminate strips according to the near surface mounted (NSM) technique and the slab SL_EBR_TO was strengthened with one laminate strip according to the externally bonded technique (EBR). Finally, two slabs were strengthened with one prestressed CFRP laminate strip, using the MA (SL_MA_TO) and GA (SL_GA_TO) systems. Three distinct types of CFRP laminate geometries were used: $10 \times 1.4 \mathrm{~mm}^{2}$ (NSM), $50 \times 1.2 \mathrm{~mm}^{2}$ (MA and GA) and $100 \times 1.2 \mathrm{~mm}^{2}$ (EBR). All the strengthened slabs were designed to achieve approximately the same ultimate load (double the ultimate load of the slab SL_REF_TO). Figure 6 presents the geometry, instrumentation and test configuration of the RC slabs. The instrumentation included LVTDs, strain gauges and load cells. A servo-controlled machine was used to perform the tests, under displacement control at a rate of $1.2 \mathrm{~mm} / \mathrm{min}$.

\section{(a)}

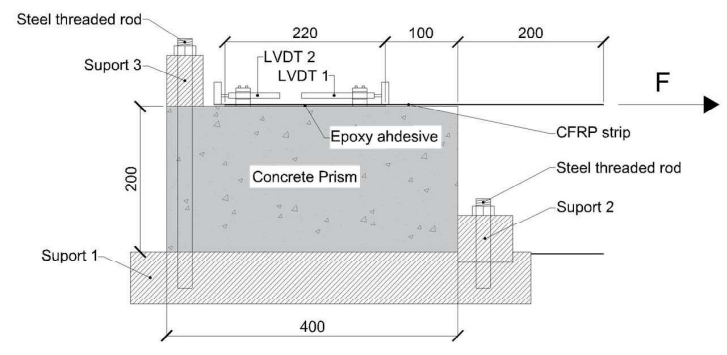

(b)

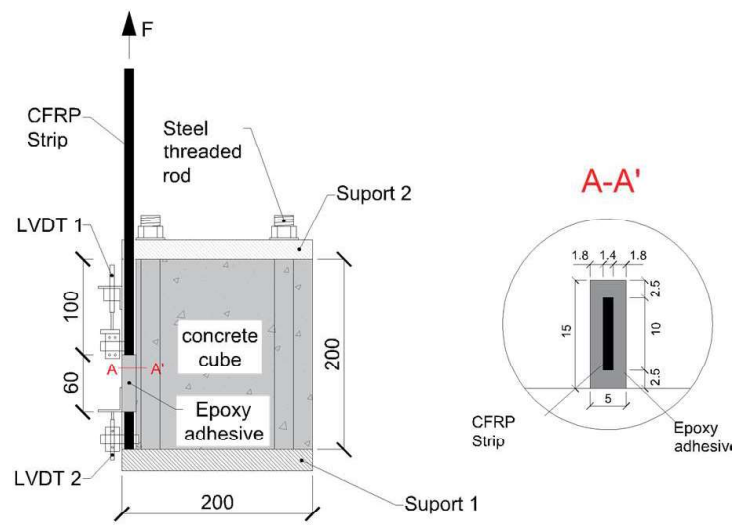

Figure 5. Specimen's geometry and test setup of bond tests of (a) EBR and (b) NSM (units in [mm]).

\subsection{Materials}

As referred before, all specimens were cast using a single batch. Six cylindrical concrete specimens (diameter/height $=150 / 300[\mathrm{~mm}]$ ) were used to evaluate the modulus of elasticity and compressive strength through the NPEN 12390-13:2013 and NP EN 12390-3:2011 standards, respectively. The average compressive strength and modulus of elasticity of the concrete (age of 28 days) was equal to $41.5 \mathrm{MPa}$ ( $\mathrm{COV}=4.4 \%$ ) and $29.1 \mathrm{GPa}(\mathrm{COV}=$ $4.7 \%)$.

Tensile properties of steel reinforcement were evaluated with the NP EN ISO 6892-1:2012 standard. Four samples with a length of $500 \mathrm{~mm}$ of each bar type were tested and the main results modulus of elasticity, $E_{s}$, Yield strength, $f_{y}$, and ultimate tensile strength, $f_{t}$ - are presented in Table 1. 
The CFRP tensile properties were also assessed using a minimum of five specimens and the experimental procedure followed was the one described by ISO 527-5:1997. The modulus of elasticity, $E_{s}$, and ultimate strength, $f_{f}$, of the laminates used in the EBR and NSM bond specimens are equal to $184.3 \mathrm{GPa}(2.9 \%)$,

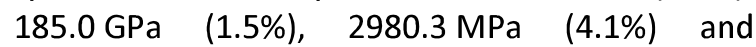
$2858.2 \mathrm{MPa}(2.0 \%)$, respectively; in the case RC slab, the values are included in Table 1.

The epoxy adhesive was also characterized during this preliminary experimental campaign. Six specimens were tested according to the ISO 527-2:2012 recommendations. The average value of the modulus of elasticity, ultimate strain, and tensile strength were equal to $6.5 \mathrm{GPa}$ $(\mathrm{Cov}=3.0 \%), \quad 0.4 \% \quad(\mathrm{Cov}=6.2 \%)$ and $19.9 \mathrm{MPa}$ $(\mathrm{CoV}=3.0 \%)$, respectively.

\subsection{Results}

\subsubsection{Bond tests}

Table 2 present the main results obtained in the EBR and NSM bond tests. In this table, $F_{\max }$ is the maximum force achieved during the test whereas $S_{\text {Imax }}$ is the slip at the loaded end at $F_{\text {max }}$. Finally, FM represents the failure mode observed in the test.

The bond EBR tests present an average maximum shear force of $30.5 \mathrm{kN}$ and the dominant failure mode was cohesive failure at the concrete.
According to the CNR [12], the expected maximum strength before CFRP debonding is equal to $505.1 \mathrm{MPa}$, whereas the mean experimental maximum strength obtained was equal to 508.7 MPa. Therefore, a good correlation between the experimental maximum strength and the expected maximum strength was observed.

(b)

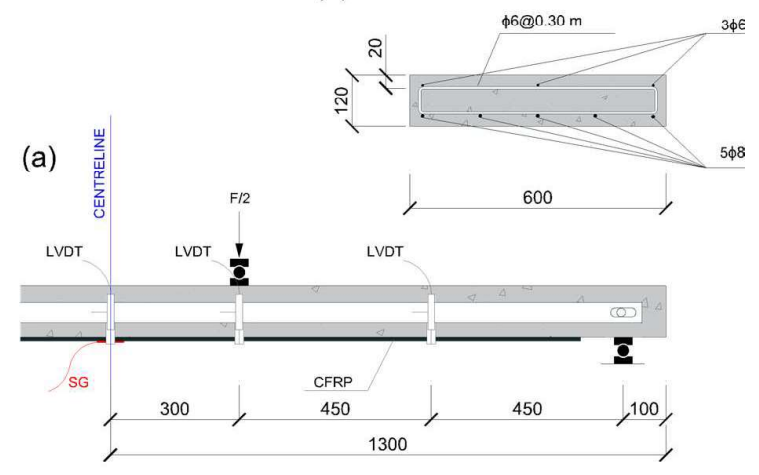

(c)

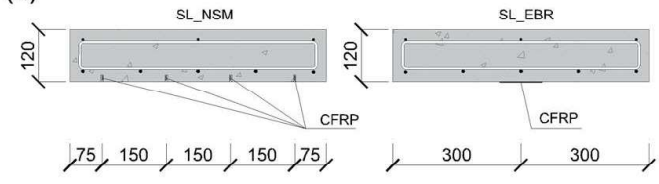

Figure 6. (a) Geometry and test configuration; cross-section for (b) reference slab; and for (c) strengthened slabs. Note: All units in [ $\mathrm{mm}]$.

Table 1. Experimental programme of RC slabs.

\begin{tabular}{|c|c|c|c|c|c|c|c|c|c|c|c|}
\hline \multirow[t]{2}{*}{ SPECIMEN } & \multirow[t]{2}{*}{$\begin{array}{c}\text { CFRP STRIP } \\
{\left[\mathrm{mm}^{2}\right]}\end{array}$} & \multirow[t]{2}{*}{$\begin{array}{c}\text { ANCHORAGE } \\
\text { TYPE }\end{array}$} & \multirow[t]{2}{*}{$\begin{array}{c}\varepsilon_{\mathrm{fp}} \\
{[\%]}\end{array}$} & \multicolumn{2}{|c|}{$\begin{array}{c}E_{s} \\
{[\mathrm{GPA}]}\end{array}$} & \multicolumn{2}{|c|}{$\begin{array}{c}f_{y} \\
{[\mathrm{MPa}]}\end{array}$} & \multicolumn{2}{|c|}{$\begin{array}{c}f_{t} \\
{[\mathrm{MPa}]}\end{array}$} & \multirow[t]{2}{*}{$\begin{array}{c}E_{f} \\
{[\mathrm{GPA}]}\end{array}$} & \multirow[t]{2}{*}{$\begin{array}{c}f_{f} \\
{[\mathrm{MPa}]}\end{array}$} \\
\hline & & & & $\Phi 6$ & $\Phi 8$ & $\Phi 6$ & $\Phi 8$ & $\Phi 6$ & $\Phi 8$ & & \\
\hline SL_REF_TO & -- & -- & -- & \multirow{2}{*}{$\begin{array}{l}219.9 \\
(1.6 \%)\end{array}$} & \multirow{2}{*}{$\begin{array}{l}209.3 \\
(7.7 \%)\end{array}$} & \multirow{2}{*}{$\begin{array}{l}543.9 \\
(1.8 \%)\end{array}$} & \multirow{2}{*}{$\begin{array}{l}551.2 \\
(0.8 \%)\end{array}$} & \multirow{2}{*}{$\begin{array}{l}670.0 \\
(0.9 \%)\end{array}$} & \multirow{2}{*}{$\begin{array}{c}635.4 \\
(0.5 \%)\end{array}$} & -- & -- \\
\hline SL_EBR_TO & $100 \times 1.2$ & -- & -- & & & & & & & $\begin{array}{c}187.2 \\
(0.9 \%) \\
\end{array}$ & $\begin{array}{l}2895.2 \\
(4.4 \%) \\
\end{array}$ \\
\hline SL_NSM_TO & $4 \times(10 \times 1.4)$ & -- & -- & $\begin{array}{r}241.4 \\
(5.3 \%) \\
\end{array}$ & $\begin{array}{l}228.1 \\
(3.2 \%) \\
\end{array}$ & $\begin{array}{l}528.2 \\
(0.7 \%) \\
\end{array}$ & $\begin{array}{l}581.3 \\
(0.6 \%) \\
\end{array}$ & $\begin{array}{r}687.1 \\
(0.7 \%) \\
\end{array}$ & $\begin{array}{l}698.3 \\
(0.3 \%) \\
\end{array}$ & $\begin{array}{l}185.0 \\
(1.5 \%) \\
\end{array}$ & $\begin{array}{l}2858.2 \\
(2.0 \%) \\
\end{array}$ \\
\hline SL_MA_TO & $50 \times 1.2$ & $\mathrm{MA}$ & 0.4 & \multirow{2}{*}{$\begin{array}{c}219.9 \\
(1.6 \%)\end{array}$} & \multirow{2}{*}{$\begin{array}{l}209.3 \\
(7.7 \%)\end{array}$} & \multirow{2}{*}{$\begin{array}{l}543.9 \\
(1.8 \%)\end{array}$} & \multirow{2}{*}{$\begin{array}{l}551.2 \\
(0.8 \%)\end{array}$} & \multirow{2}{*}{$\begin{array}{l}670.0 \\
(0.9 \%)\end{array}$} & \multirow{2}{*}{$\begin{array}{c}635.4 \\
(0.5 \%)\end{array}$} & \multirow{2}{*}{$\begin{array}{c}184.3 \\
(2.9 \%)\end{array}$} & \multirow{2}{*}{$\begin{array}{l}2980.3 \\
(4.1 \%)\end{array}$} \\
\hline SL_GA_TO & $50 \times 1.2$ & $\mathrm{GA}$ & 0.4 & & & & & & & & \\
\hline
\end{tabular}

Note: the values between parentheses are the corresponding coefficients of variation (CoV). 
Table 2. Main results of EBR and NSM bond tests (average results of 4 specimens).

\begin{tabular}{lccc}
\hline \multirow{2}{*}{ Series } & $\begin{array}{c}\mathbf{F}_{\max } \\
{[\mathbf{k N}]}\end{array}$ & $\begin{array}{c}\mathbf{S}_{\text {Imax }} \\
{[\mathbf{m m}]}\end{array}$ & FM \\
\hline \multirow{2}{*}{ SLT-EBR } & 30.52 & 0.53 & $\mathrm{D}+\mathrm{C}[2]$ \\
\multirow{2}{*}{ DPT-NSM } & $(11.61 \%)$ & $(15.13 \%)$ & $\mathrm{C}[2]$ \\
& 28.21 & 0.54 & $\mathrm{D}[4]$ \\
\hline
\end{tabular}

Notes: Values between parentheses are the corresponding coefficient of variations; $\mathrm{D}=$ Debonding at laminate-adhesive interface, $\mathrm{C}=$ Cohesive failure of concrete, values between brackets are the $n$. of specimens where this FM occurred.

The maximum pull-out force obtained from the bond NSM tests is close to $28.2 \mathrm{kN}$. In the CFRP strip $\left(10 \times 1.4 \mathrm{~mm}^{2}\right)$ this load corresponds to a stress level of $2014.3 \mathrm{MPa}$, which represents $70.4 \%$ of its tensile strength. In comparison to the bond EBR tests, it is clear that with a smaller bonded length $(60 \mathrm{~mm})$ the NSM technique can achieve higher ultimate stress levels. These observations have been also observed in other works.

\subsubsection{Flexural tests with RC slabs}

Table 3 presents the main results obtained from the slab tests and Figure 7 presents the relationship between force and mid-span displacement. In general, all slabs present three test phases: (i) elastic phase, (ii) cracked phase and, (iii) phase after steel yielding. Flexural stiffness $K_{1}$ is similar in all slabs - $9.1 \mathrm{kN} / \mathrm{mm}(\mathrm{CoV}=12 \%)$ - because all strengthened slabs present low amount of strengthening reinforcement.

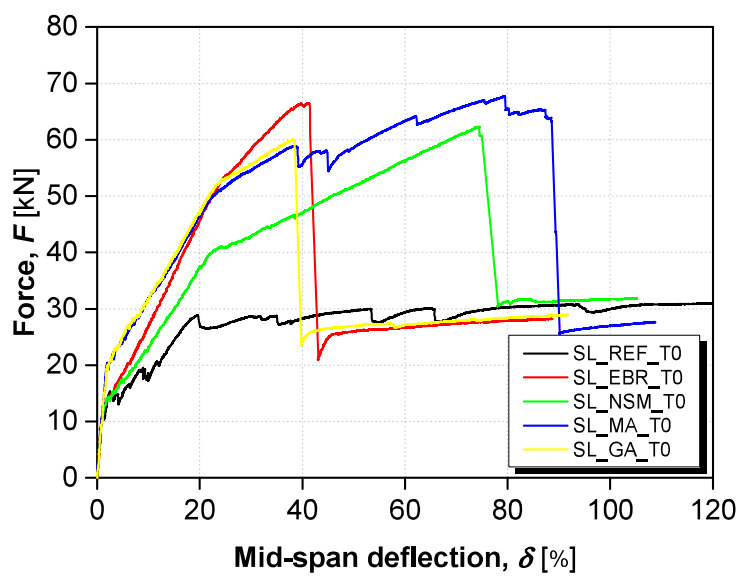

Figure 7. Force vs. mid-span displacement obtained on the slab tests.

In the following stage, the cracking of the concrete reduces the slabs' flexural stiffness $K_{\| 1}$. The strenghtening, delayed the crak initiation $\left(\delta_{c r}, F_{c r}\right)$, specially on the prestressed slabs. After the yielding of the steel, the influence of the CFRP reinforceemnt is clearly noticed in the flexural stiffness, $K_{\text {III, }}$ of each slab, as the CFRP material becomes responsible to carry the aditional load increments (steel exibits small hardening modulus). The steel yielding occurred for similar loads $\left(F_{y}\right)$ and mid-span deflections $\left(\delta_{y}\right)$ in all the strenghtened slabs, except to the SL_NSM_TO, where the $F_{y}$ was about $77 \%$ of the observed in other slabs.

Table 3. Main results of slab tests.

\begin{tabular}{|c|c|c|c|c|c|c|c|c|c|c|c|c|c|}
\hline \multirow[t]{2}{*}{ Specimen } & \multicolumn{3}{|c|}{ Stiffness } & \multicolumn{2}{|c|}{$\begin{array}{c}\text { Crack } \\
\text { initiation }\end{array}$} & \multicolumn{2}{|c|}{ Yielding } & \multicolumn{3}{|c|}{ Failure } & \multicolumn{2}{|c|}{$\begin{array}{c}\text { Efficiency and } \\
\text { ductility } \\
\text { parameters }\end{array}$} & \multirow[t]{2}{*}{ FM } \\
\hline & $\begin{array}{c}\mathbf{K}_{\mathbf{I}} \\
{[\mathrm{kN} / \mathrm{mm}]}\end{array}$ & $\begin{array}{c}\mathbf{K}_{\mathrm{II}} \\
{[\mathrm{kN} / \mathrm{mm}]}\end{array}$ & $\begin{array}{c}\mathbf{K}_{\mathrm{III}} \\
{[\mathrm{kN} / \mathrm{mm}]}\end{array}$ & $\begin{array}{c}\boldsymbol{\delta}_{\mathrm{cr}} \\
{[\mathrm{mm}]}\end{array}$ & $\begin{array}{c}\mathbf{F}_{\mathbf{c r}} \\
{[\mathrm{kN}]}\end{array}$ & $\begin{array}{c}\boldsymbol{\delta}_{\mathbf{y}} \\
{[\mathrm{mm}]}\end{array}$ & $\begin{array}{c}F_{y} \\
{[k N]}\end{array}$ & $\begin{array}{c}\boldsymbol{\delta}_{\max } \\
{[\mathrm{mm}]}\end{array}$ & $\begin{array}{l}F_{\max } \\
{[k N]}\end{array}$ & $\begin{array}{c}\varepsilon_{\mathrm{fmax}} \\
{\left[\times 10^{-3}\right]}\end{array}$ & $\begin{array}{c}\mathbf{F}_{\max } / \mathbf{F}_{\mathbf{y}} \\
{[-]}\end{array}$ & $\begin{array}{c}\delta_{\max } / \delta_{y} \\
{[-]}\end{array}$ & \\
\hline SL_REF_TO & 7.51 & 1.30 & -- & 1.17 & 12.30 & 19.58 & 28.82 & 120.47 & 30.96 & -- & -- & -- & -- \\
\hline SL_EBR_TO & 10.82 & 1.87 & 0.98 & 1.32 & 12.63 & 24.64 & 53.22 & 41.23 & 66.47 & 6.65 & 1.25 & 1.67 & $\mathrm{D}$ \\
\hline SL_NSM_TO & 9.14 & 1.35 & 0.44 & 2.41 & 14.44 & 22.28 & 39.94 & 74.44 & 62.28 & 14.09 & 1.56 & 3.34 & $\mathrm{~F}$ \\
\hline SL_GA_TO & 9.95 & 1.56 & 0.55 & 2.00 & 20.01 & 23.26 & 52.04 & 38.27 & 59.98 & 7.00 & 1.15 & 1.65 & D \\
\hline SL_MA_TO & 10.59 & 1.57 & 0.55 & 2.04 & 20.41 & 22.19 & 49.69 & 79.24 & 67.62 & 12.24 & 1.36 & 3.57 & $\mathrm{~F}$ \\
\hline
\end{tabular}

Notes: $\mathrm{K}_{\mathrm{I}}, \mathrm{K}_{\mathrm{II}}, \mathrm{K}_{\mathrm{III}}=$ Flexural stiffness at elastic, cracking and yielding stages; $\mathrm{F}_{\mathrm{cr}}, \mathrm{F}_{\mathrm{y}}, \mathrm{F}_{\max }=$ cracking, yielding and ultimate loads; $\delta_{c r}, \delta_{y}, \delta_{\max }=$ mid-span displacement at $F_{c r}, F_{y}, F_{\max } ; \varepsilon_{f \max }=$ CFRP laminate strain at $F_{\max } ; F_{\max } / F_{y}$ and $\delta_{\max } / \delta_{y}=$ ductility indexes; Failure Modes (FM): D = Detachment of CFRP laminate; F = CFRP rupture. 
SL_NSM_TO failed by CFRP rupture, for the maximum load, $F_{\max }$, of $62.3 \mathrm{kN}$. Similarly, the prestressed slab SL_MA_T0 also failled by CFRP rutpure when $F_{\max }=67.62 \mathrm{kN}$. The remaining two strengthened slabs (SL_EBR_TO and SL_GA_TO) failed by CFRP strip debonding. The two prestressed slabs exibit a similar behaviour until steel yielding. At this test stage, the debonding of the CFRP laminate starts to occurr, however, the metalic anchor plates of in the SL_MA_TO avoided the premature failure, whereas in the SL_GA_TO (gradient anchorage), the initial CFRP strip debonding was rapidly transformed into the complete strip detachment.

Ultimatly, as proviously referred, each strenghtened specimen was designed to support the maximum load of $60 \mathrm{kN}$ (duplicate the load carrying capacity of the reference slab). The test results confirm that the strenghtening solutions were adequate to achive the predefined goal.

\section{Conclusions}

The present work presented a general description and the main preliminary results of an ongoing research project whose main goal is to study the long-term structural behaviour and durability performance of $R C$ elements strengthened in flexure with CFRP laminates according to the EBR and NSM techniques, under various real environments.

At the onset of the installation of the experimental stations, an experimental campaign composed of pull-out tests on NSM specimens, single-lap shear tests on EBR specimens, and flexural tests on RC slabs was carried out. From the obtained results the following conclusions can be pointed out: (i) good correlation between the experimental maximum strength and the expected maximum strength was observed with the single-lap shear tests on EBR specimens; (ii) the pull-out tests on NSM specimens showed a more efficient use of the CFRP material ( $70.4 \%$ of its tensile strength) than the EBR specimens; (iii) all the slabs were able to reach the predefined load of $60 \mathrm{kN}$; (iv) slabs SL_NSM_TO and SL_MA_TO presented the highest CFRP strain at failure, thus allowing more efficiency in the use of the CFRP laminate strips.

\section{Acknowledgements}

This work is supported by FEDER funds through the Operational Program for Competitiveness Factors COMPETE and National Funds through FCT Portuguese Foundation for Science and Technology under the project FRPLongDur - POCI-01-0145FEDER-016900 (FCT PTDC/ECM-EST/1282/2014) and partly financed by the project POCI-01-0145FEDER-007633. The authors thank all the companies that supported and contributed for the development of this study, mainly: S\&P Clever Reinforcement Ibérica, EDP, APDL, Sika Portugal, Tecnipor, Vialam, Hilti, Artecanter and Navarra. The second author also wishes to acknowledge the grant SFRH/BD/131259/2017 provided by FCT.

\section{References}

[1] Tatar J., and Hamilton H.R. Comparison of laboratory and field environmental conditioning on FRP-concrete bond durability. Construction and Building Materials. 2016; 122: 525-536.

[2] Kabir M. I., Shrestha R., and Samali, B. Effects of applied environmental conditions on the pull-out strengths of CFRP-concrete bond. Construction and Building Materials. 2016; 114: 817-830.

[3] Hassan S. A., Gholami M., Ismail Y. S. and Sam A. R. M. Characteristics of concrete/CFRP bonding system under natural tropical climate. Construction and Building Materials. 2015; 77: 297-306.

[4] Mohd Hashim M. H., Mohd Sam A. R. and Hussin M. W. Experimental investigation on the effect of natural tropical weather on interfacial bonding performance of CFRPconcrete bonding system. Journal of Engineering Science and Technology. 2016; 11: 584-604.

[5] Fernandes P., Sena-Cruz J., Xavier J., Silva P., Pereira E. and Cruz J. Durability of bond in NSM CFRP-concrete systems under different environmental conditions. Composites Part B: Engineering. 2018; 138: 19-34.

[6] Hsieh C. T., Lin Y. and Lin S. K. Impact-echo method for the deterioration evaluation of near-surface mounted CFRP strengthening under outdoor exposure conditions. 
Materials and Structures/Materiaux et Constructions. 2017; 50.

[7] Sen, R. Developments in the durability of FRP-concrete bond. Construction and Building Materials. 2015; 78: 112-125.

[8] Al-Tamimi A. K., Hawileh R. A., Abdalla J. A., Rasheed H. A. and Al-Mahaidi R. Durability of the bond between CFRP plates and concrete exposed to harsh environments. Journal of Materials in Civil Engineering. 2015; 27.

[9] Bhashya V., Kumar S. S., Ramesh G., Bharatkumar B. H., Krishnamoorthy T. S. and lyer N. R. Long term studies on FRP strengthened concrete specimens. Indian Journal of Engineering and Materials Sciences. 2015; 22: 465-472.

[10] Soares S., Sena-Cruz J., Cruz J.R., Fernandes $P$. Influence of surface preparation method on the bond behavior of externally bonded CFRP reinforcements in concrete. Materials. 2019; 12(3) 414: 1-20.

[11] Correia L., Teixeira T., Michels J., Almeida J., Sena-Cruz J. Flexural behaviour of RC slabs strengthened with prestressed CFRP strips using different anchorage systems. Composites Part B: Engineering. 2015; 81: 158-170.

[12] CNR. Guide for the design and construction of externally bonded FRP systems for strengthening existing structures. 2013. 